\title{
Operational and economic analysis of a Velox- type combined heat \& power plant with a throttle valve
}

\author{
Krystian Smołka ${ }^{1 *}$, Piotr Wiśniewski ${ }^{1}$, Mirosław Majkut ${ }^{1}$, and Stawomir Dykas ${ }^{1}$ \\ ${ }^{1}$ Silesian University of Technology, Department of Power Engineering and Turbomachinery, \\ Konarskiego 18, 44-100 Gliwice, Poland.
}

\begin{abstract}
For many years, the Department of Power Engineering and Turbomachinery of the Silesian University of Technology has been using a small-capacity (about $500 \mathrm{~kW}_{\mathrm{e}}$ ) steam-gas power plant. Based on many years of experience in operation of this power plant utilizing the Velox-type gas-steam system, an idea arose to modify this type of thermal power cycle to create a combined heat and power (CHP) plant of small capacity, dedicated for distributed heat and power production or production process steam with high temperature. Previous thermodynamic and economic analysis of that type of low-power CHP plant confirmed many advantages of using this type of solution in low-power engineering. The new idea is to add a throttle valve between the economizer and the evaporator for the reference cycle of the gas-steam Velox-type CHP plant. It was further assumed that water would partially be vaporized on the valve. This paper presents a thermodynamic and economic analysis of this type of a system with an added throttle valve. Downstream the valve, the evaporated water fraction is fed directly into the steam superheater. It is determined how such a retrofit affects the system thermodynamic and economic characteristics. The system is modelled in the EBSILON ${ }^{\circledR}$ Professional 14 software.
\end{abstract}

\section{Introduction}

Historically, the first power system using a gas-steam turbine combination was the one where a steam generator was incorporated into the gas turbine system to replace the classical combustion chamber. The concept originated in the Swiss company Brown Boveri. This Velox-type system, as it was called, was patented in 1932 and in 1939 it was used for the first time to produce electricity. Considering the amount of generated steam, the Velox steam generator has a compact design and a relatively small heat transfer surface, especially in the evaporator. This is due to the fact that the heat exchange process in the combustion chamber takes place in overpressure, which intensifies the heat transfer between exhaust gases and water and steam in the tubes of the evaporator or steam superheaters. The high velocity of exhaust gases in such a system enables effective utilization of the combustion chamber [1]. The use of such combined systems in professional power engineering contributed to the

\footnotetext{
* Corresponding author: krystian.smolka@polsl.pl
} 
creation of high-efficient heat and electricity generation systems, including the first gassteam cogeneration plant.

The advantages of classic gas-steam systems include the following [2, 3]:

- high efficiency of the fuel chemical energy conversion into electricity and heat,

- lower investment costs compared to conventional combined heat and power plants,

- flexible selection and use of fuels; combined systems can effectively fire natural gas, other gaseous fuels, refined oil and other oil fuels,

- high thermal flexibility from a short start-up to full-load operation; moreover, gassteam systems maintain constant and high efficiency at loads of $70 \div 100 \%$ of the rated power,

- short investment completion time,

- high reliability and availability,

- relatively low maintenance and operating costs and a high degree of automation of the operating process,

- very favourable ecological characteristics, much lower emissions of harmful substances and lack of solid combustion waste; a very important advantage, especially in today's power industry, which has to cope with increasingly stringent emission standards.

On the other hand, the disadvantages of combined systems include as follows:

- higher price of combined-system products compared to conventional systems,

- high price of fuel,

- dependence of the gaseous fuel availability and price on strictly political factors; natural gas and oil, which are usually used in such systems, are strategic fuels; they are extracted in specific regions of the world and the need to build pipelines transporting the fuel over long distances substantially increases investment costs.

Considering the above, classic gas-steam systems can be used effectively in high-power engineering.

Using the experience gained so far from the operation of the Velox-type gas-steam system at the Department of Power Engineering and Turbomachinery of the Silesian University of Technology [4] and the technological progress which, among others, makes it possible to use materials enabling production of steam with much higher parameters than in the early days of this type of combined cycles, an idea originated to modify the system to create a lowpower combined heat and power (CHP) plant intended for distributed heat and electricity generation or production of high-temperature process steam. Previous thermodynamic and economic analyses [5-7] of a numerical reference model of a system of a Velox-type lowpower CHP plant and its comparison with a classic gas-steam cycle $[3,8]$ led to the following conclusions:

- a Velox-type plant can operate at much lower loads than a classic CHP plant,

- a steam-gas Velox-type power unit makes it possible to use higher temperatures of live steam,

- a Velox-type plant can be much cheaper than a classic CHP plant,

- a Velox-type system can successfully be fired not only with natural gas but also with alternative gaseous fuels, and the cost of adapting such a system for operation with other fuels is not high.

The resulting general conclusion is that the proposed Velox-type gas-steam system keeps many advantages of the classic gas-steam configuration, eliminating at the same time some of the downsides of the latter; it could well be used as a low-power system in distributed power generation.

In order to improve the efficiency of the created reference system of the gas-steam Veloxtype CHP plant and to reduce the size of some of the heat exchangers necessary in the cycle, 
it was proposed to add a throttle valve between the economizer and the evaporator. It was further assumed that water would partially be vaporized on the valve. The paper presents an analysis of this type of a system with an added throttle valve. Downstream the valve, the evaporated water fraction is fed directly into the steam superheater. It is determined how such a retrofit affects the system thermodynamic and economic characteristics. All the analyses presented herein are performed using the EBSILON ${ }^{\circledR}$ Professional 14 software.

\section{Thermal power cycles and parameters}

\subsection{Reference Cycle}

The Velox-type CHP plant (Fig. 1) is characterized by a much higher ratio of electricity obtained from the steam turbine and the gas turbine, respectively, compared to classic gassteam cycles which are now mostly in use. More steam with higher enthalpy is produced from the same amount of fuel [6]. The Velox-type CHP plant system was modelled in the EBSILON® Professional 14 program according to the technological structure shown in Fig. 1.

Table 1 presents the basic parameters for the nominal load of the reference cycle of the Velox-type CHP plant under consideration. It sets out all important parameters for the cycle presented above, together with the efficiency of main and auxiliary machines.

It should be noted that the net efficiency of electricity production is not high, which is expected for this type of cycles with such small power outputs, whereas the efficiency of cogeneration is in the range of many other CHP plants with different technological structures [3].

In addition, Table 2 shows the calculated parameter $\mathrm{kA}$ for all heat exchangers used in the reference cycle of the considered CHP plant. It can be used to estimate the heat exchangers size and their surface area.

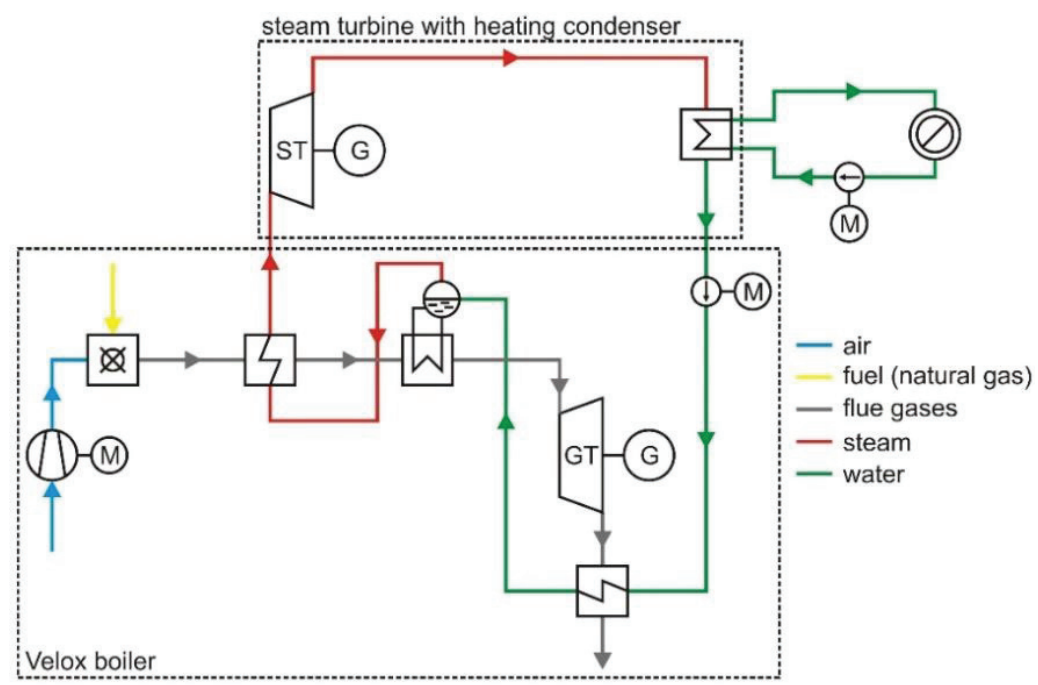

Fig. 1. Velox-type CHP plant schematic diagram - reference cycle. 
Table 1. Basic operating parameters for the reference cycle of the Velox-type CHP plant under consideration (nominal load).

\begin{tabular}{|c|c|c|}
\hline Parameter & Value & Unit \\
\hline Fuel mass flow & 0.0013 & $\mathrm{~kg} / \mathrm{s}$ \\
\hline Exhaust gas mass flow & 0.101 & $\mathrm{~kg} / \mathrm{s}$ \\
\hline Exhaust gas temperature upstream the expander & 333 & ${ }^{\circ} \mathrm{C}$ \\
\hline Exhaust gas pressure upstream the expander & 300 & $\mathrm{kPa}(\mathrm{a})$ \\
\hline Exhaust gas temperature downstream the expander & 192 & ${ }^{\circ} \mathrm{C}$ \\
\hline Live steam temperature & 680 & ${ }^{\circ} \mathrm{C}$ \\
\hline Live steam pressure & 2000 & $\mathrm{kPa}(\mathrm{a})$ \\
\hline Steam mass flow & 0.014 & $\mathrm{~kg} / \mathrm{s}$ \\
\hline Steam temperature downstream the steam turbine & 265 & ${ }^{\circ} \mathrm{C}$ \\
\hline Steam pressure downstream the steam turbine & 100 & $\mathrm{kPa}(\mathrm{a})$ \\
\hline Power on the compressor shaft & 12.989 & $\mathrm{~kW}$ \\
\hline Power on the feed water pump shaft & 0.034 & $\mathrm{~kW}$ \\
\hline Power on the heating water circuit pump shaft & 0.008 & $\mathrm{~kW}$ \\
\hline Power on the gas turbine shaft & 15.141 & $\mathrm{~kW}$ \\
\hline Power on the steam turbine shaft & 11.897 & $\mathrm{~kW}$ \\
\hline Inlet temperature of the heating water circuit & 30 & ${ }^{\circ} \mathrm{C}$ \\
\hline Outlet temperature of the heating water circuit & 94.6 & ${ }^{\circ} \mathrm{C}$ \\
\hline Heat flux from the heating water circuit & 35.547 & $\mathrm{~kW}$ \\
\hline Exhaust gas temperature downstream the superheater & 576 & ${ }^{\circ} \mathrm{C}$ \\
\hline Exhaust gas temperature downstream the evaporator & 333 & ${ }^{\circ} \mathrm{C}$ \\
\hline Exhaust gas temperature downstream the economizer & 146 & ${ }^{\circ} \mathrm{C}$ \\
\hline Water temperature upstream the economizer & 99.9 & ${ }^{\circ} \mathrm{C}$ \\
\hline Water temperature downstream the economizer & 184 & ${ }^{\circ} \mathrm{C}$ \\
\hline Steam temperature downstream the evaporator & 213 & ${ }^{\circ} \mathrm{C}$ \\
\hline Gas turbine internal efficiency & 90 & $\%$ \\
\hline Steam turbine internal efficiency & 90 & $\%$ \\
\hline Efficiency of generators & 98.6 & $\%$ \\
\hline Compressor efficiency & 85 & $\%$ \\
\hline Efficiency of pumps & 80 & $\%$ \\
\hline Electric efficiency of motors driving the pumps & 95 & $\%$ \\
\hline Mechanical efficiency of motors (for pumps and compressor) & 99.8 & $\%$ \\
\hline Net efficiency of electricity production & 20.4 & $\%$ \\
\hline Net efficiency of heat and electricity production & 76.7 & $\%$ \\
\hline
\end{tabular}

The assumed live steam temperature of $680^{\circ} \mathrm{C}$ may seem extremely high for this type of cycle, especially for a steam turbine. However, technological progress in recent years has led to a significant development of nickel-based alloys that can be successfully used in the construction of turbine components. Alloys of this type have been widely used in the production of gas turbines for years, and have recently been introduced to the construction of high-power steam turbines in the search for materials for ultra-supercritical steam parameters. In the proposed cycle, there are no problems that arose in the production of large turbines for ultra-supercritical steam parameters (much lower pressure was used, and the turbine will not be large), therefore it will be possible to successfully use nickel-based alloys in its construction and experience obtained from gas turbines.

The Table 1 also shows that the assumed internal efficiency of the steam turbine is $90 \%$. This value may seem too high for a turbine with such a low power output $(\sim 12 \mathrm{~kW})$, however, the assumption was to propose a cycle for a power of up to $500 \mathrm{~kW}$, hence the efficiency was adopted at a higher level than would be expected for very low power turbines. In future research, when we increase the nominal power of the entire system, this efficiency should be 
assumed at a level appropriate for modern steam turbines with a specific power, which will entail a slight change in the efficiency of the entire system. It should be added that the reduction of the internal efficiency of the steam turbine entails an increase in the steam temperature downstream of the turbine, and thus an increase in heat production.

Table 2. Surface area of heat exchangers (kA parameter) for the reference cycle of the Velox-type CHP plant under consideration (nominal load).

\begin{tabular}{|c|c|c|}
\hline Parameter & Value & Unit \\
\hline Economizer & 0.230 & $\mathrm{~kW} / \mathrm{K}$ \\
\hline Evaporator & 0.126 & $\mathrm{~kW} / \mathrm{K}$ \\
\hline Superheater & 0.125 & $\mathrm{~kW} / \mathrm{K}$ \\
\hline Heat exchanger in the heating water circuit & 1.449 & $\mathrm{~kW} / \mathrm{K}$ \\
\hline Total & 1.930 & $\mathrm{~kW} / \mathrm{K}$ \\
\hline
\end{tabular}

\section{Cycle with a throttle valve}

The proposed modification of the system consisted in increasing the feed water pressure upstream the economizer and then lowering this pressure downstream the economizer to the value required upstream the steam turbine according to the reference cycle. The lowering of the pressure between the economizer and the evaporator takes place in the throttle valve (cf. Fig. 2). Obviously, the application of such a solution in the system under consideration without any additional assumptions would only lower the efficiency of the entire system because the feed water pump would require a bigger input of work at the same generated power, both electric and thermal. Only the power of the own-needs system would be increased. For example, if the pressure upstream the steam turbine is maintained at the level of $2 \mathrm{MPa}$ (reference cycle) and the pressure downstream the feed water pump is increased to $5 \mathrm{MPa}$, the efficiency of the entire system decreases by about 0.1 percentage points. It is therefore assumed that at isenthalpic throttling a small part of water has a chance to evaporate which, if this part of the evaporated water is fed directed to the steam superheater, should increase the system efficiency. An additional advantage may be a reduction in the size of the evaporator, which may translate into lower investment outlays.

Figure 2 presents a schematic diagram of the cycle described above, which - like the reference cycle - was modelled in the EBSILON ${ }^{\circledR}$ Professional 14 program. It can be seen that the saturated steam evaporated downstream the throttle valve is separated from the liquid phase in the separator and then fed directly into the evaporator. The rest of the water is traditionally directed to the evaporator and then to the superheater.

It should be noted that in order for the water downstream the throttle valve to evaporate at least in a small part, it is necessary to ensure its appropriate temperature downstream the economizer. This leads to another assumption, i.e. that the temperature of water with higher pressure (upstream the throttle valve) is equal to the saturation temperature of water with lower pressure (downstream the throttle valve). The above assumptions were taken into account to establish the input nominal parameters of the system (cf. Table 3). The internal efficiencies of individual machines and devices making up the cycle, which are not included in the table below, are assumed to be the same as in the reference cycle (cf. Table 1). 


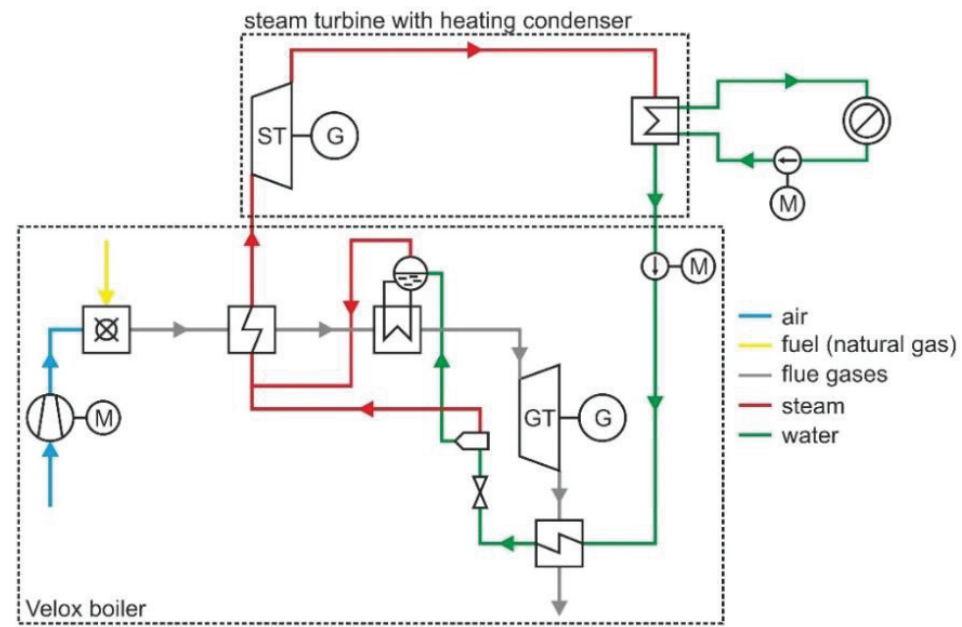

Fig. 2. Velox-type CHP plant schematic diagram - cycle with a throttle valve.

Comparing the data shown in Table 3 to the reference cycle, it can be seen that while the data for the cycle of the steam turbine with the condenser and the heating water circuit are the same for both systems, the parameters in the Velox boiler cycle are different. These differences are forced by the introduced modifications and the assumptions adopted for the cycle with the throttle valve.

Table 3. Basic operating parameters for the cycle with a throttle valve of the Velox-type CHP plant under consideration (nominal load).

\begin{tabular}{|l|c|c|}
\hline \multicolumn{1}{|c|}{ Parameter } & Value & Unit \\
\hline Fuel mass flow & 0.0013 & $\mathrm{~kg} / \mathrm{s}$ \\
\hline Exhaust gas mass flow & 0.101 & $\mathrm{~kg} / \mathrm{s}$ \\
\hline Exhaust gas temperature upstream the expander & 363 & ${ }^{\circ} \mathrm{C}$ \\
\hline Exhaust gas pressure upstream the expander & 300 & $\mathrm{kPa}(\mathrm{a})$ \\
\hline Exhaust gas temperature downstream the expander & 216 & ${ }^{\circ} \mathrm{C}$ \\
\hline Live steam temperature & 680 & ${ }^{\circ} \mathrm{C}$ \\
\hline Live steam pressure & 2000 & $\mathrm{kPa}(\mathrm{a})$ \\
\hline Steam mass flow & 0.014 & $\mathrm{~kg} / \mathrm{s}$ \\
\hline Steam temperature downstream the steam turbine & 265 & ${ }^{\circ} \mathrm{C}$ \\
\hline Steam pressure downstream the steam turbine & 100 & $\mathrm{kPa}(\mathrm{a})$ \\
\hline Water pressure downstream the pump & 5000 & $\mathrm{kPa}(\mathrm{a})$ \\
\hline Water temperature downstream the pump & $\mathrm{t}_{\mathrm{s}}(\mathrm{p}=2000 \mathrm{kPa})=213$ & ${ }^{\circ} \mathrm{C}$ \\
\hline Inlet temperature of the heating water circuit & 30 & ${ }^{\circ} \mathrm{C}$ \\
\hline Outlet temperature of the heating water circuit & 94.6 & ${ }^{\circ} \mathrm{C}$ \\
\hline Exhaust gas temperature downstream the superheater & 580 & ${ }^{\circ} \mathrm{C}$ \\
\hline Exhaust gas temperature downstream the evaporator & 363 & ${ }^{\circ} \mathrm{C}$ \\
\hline Exhaust gas temperature downstream the economizer & 156 & ${ }^{\circ} \mathrm{C}$ \\
\hline Water temperature upstream the economizer & 100 & ${ }^{\circ} \mathrm{C}$ \\
\hline Water temperature downstream the economizer & 213 & ${ }^{\circ} \mathrm{C}$ \\
\hline Steam temperature downstream the evaporator & 213 & ${ }^{\circ} \mathrm{C}$ \\
\hline
\end{tabular}

The considered system efficiency of both electricity production and combined heat and power generation depends on the adopted degree of water evaporation during throttling. For this 
reason, these values are not given in the table above. Their analysis will be presented further below.

\section{Thermodynamic analysis of a Velox-type CHP plant with a throttle valve}

As already mentioned, to model the investigated system correctly, it is assumed that some water will evaporate during isenthalpic throttling between the economizer and the evaporator. The ideal situation would be $100 \%$ water evaporation on the throttle valve, which is physically impossible. Therefore, in order to illustrate the impact of the amount of evaporated water on the system characteristics, a few evaporation levels within the range of $1 \div 10 \%$ are assumed. Figure 3 presents how the efficiency of the entire system, together with the amount of produced electric and thermal energy, as well as the sum of these energies in cogeneration change depending on the adopted level of evaporation.

As indicated by Fig. 3, the efficiency of the entire system increases with a rise in the level of water evaporation on the throttle valve, which is in fact expected. However, after the proposed changes are applied in the cycle, for the water evaporation level of up to $4 \%$, the presented parameters of the system are lower or the same as for the cycle before the modifications. Only if the water evaporation level is maintained at about $5 \%$, does the efficiency exceed the efficiency of the reference cycle. Analysing the change in energy production occurring with changes in the adopted level of evaporation, it can be observed that the level of electricity production increases very slightly, while bigger differences can be noticed for the production of heat only.

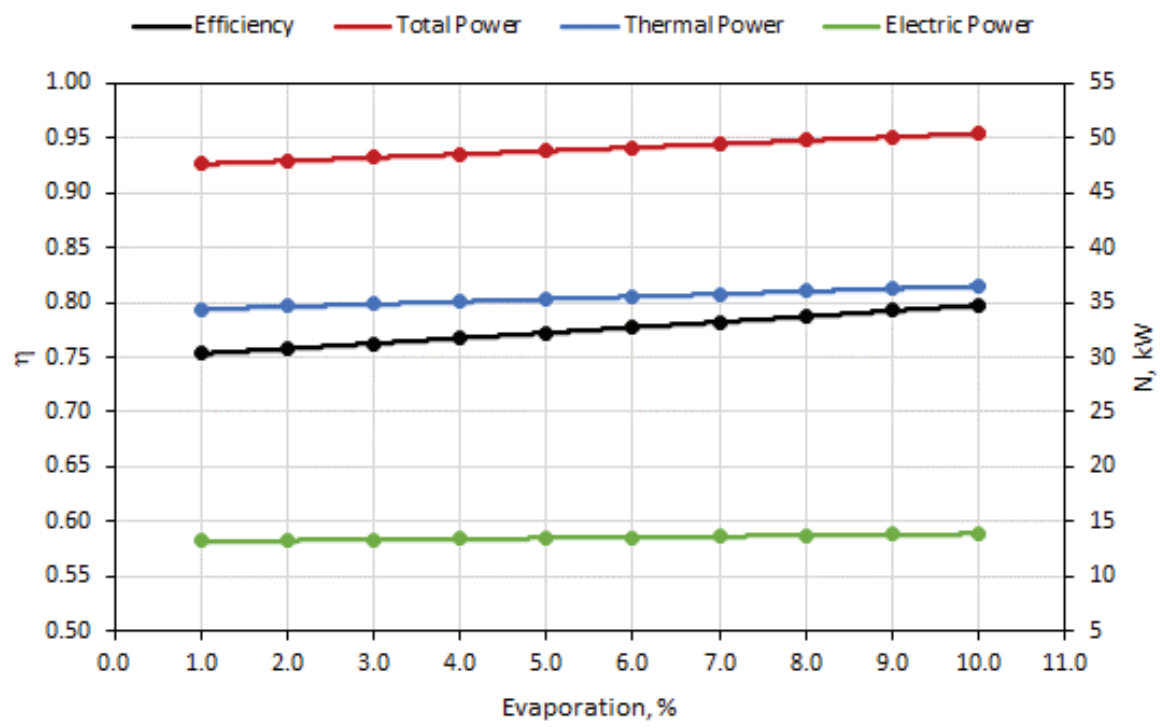

Fig. 3. Change in efficiency and energy production for a cycle with a throttle valve depending on the adopted level of evaporation.

It follows from the above that the system profitability strongly depends on the amount of water evaporated during throttling and on whether it is electricity that is produced only or whether electricity and heat are cogenerated. 
For example, the cycle net efficiency at the assumed level of evaporation of 5\% totals $77.2 \%$. This corresponds to the production of $13.5 \mathrm{~kW}$ of electricity and $35.3 \mathrm{~kW}$ of thermal energy, which means the total of $48.8 \mathrm{~kW}$ of energy obtained in cogeneration.

Figure 4 illustrates changes in the efficiency of the entire cycle and in the heat transfer surface areas for the exchangers included in the Velox boiler cycle depending on the adopted level of evaporation. It can be seen that with a rise in the evaporation level, the heat transfer surface area of the economizer and of the superheater should be increased. It is only the evaporator heat transfer surface area that decreases slightly with an increase in the adopted level of evaporation on the valve.

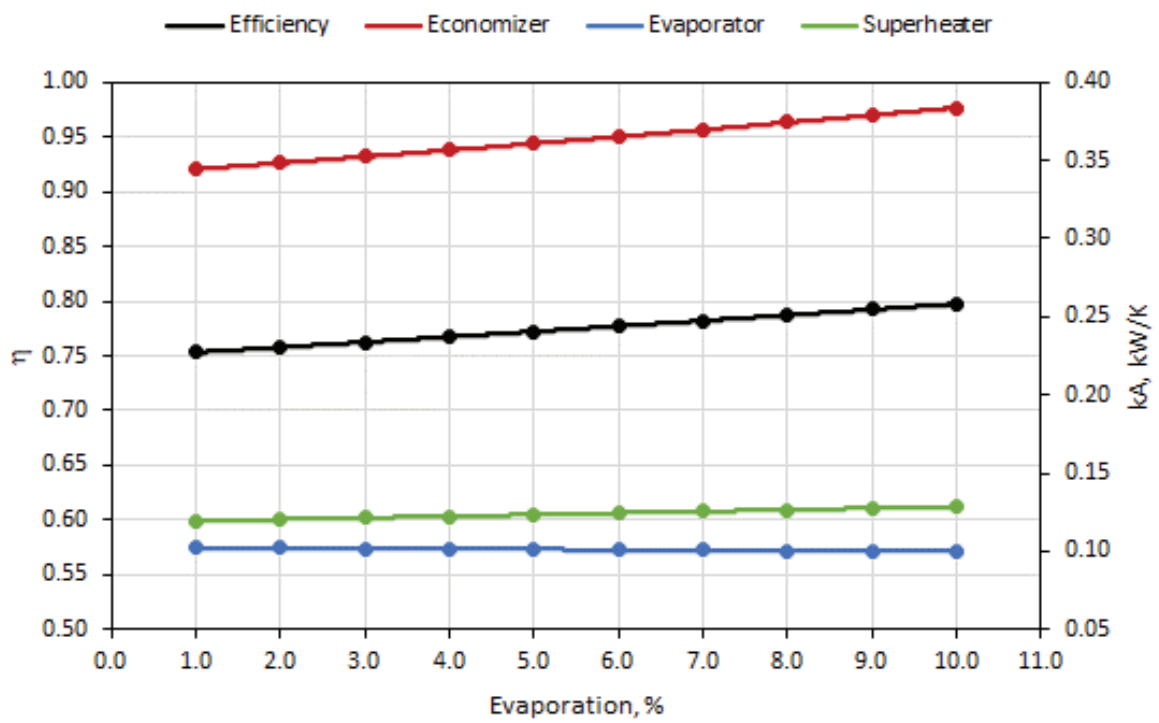

Fig. 4. Change in efficiency and in parameter kA for the exchangers included in the Velox boiler cycle for a system with a throttle valve depending on the adopted level of evaporation.

Looking at the case with the assumed evaporation level of 5\% again, it can be seen that the kA parameter, through which the heat transfer surface area of individual exchangers can be estimated, totals $0.361 \mathrm{~kW} / \mathrm{K}$ for the economizer, $0.101 \mathrm{~kW} / \mathrm{K}$ for the evaporator and $0.124 \mathrm{~kW} / \mathrm{K}$ for the superheater.

In order to better illustrate the effect of the evaporation level on the heat transfer surface area for the entire system (including the heat exchanger in the heating water circuit), this trend is shown in Fig. 5. As it can be seen here, the heat transfer surfaces in the entire range of the assumed evaporation level would have to be larger compared to the reference cycle. For example, the sum of the values of the kA parameter for all heat exchangers in the cycle at the assumed evaporation level of $5 \%$ is $2.024 \mathrm{~kW} / \mathrm{K}$, which is an increase by about $4.9 \%$ for the sum of all heat exchange surfaces in the cycle with the throttle valve compared to the reference cycle. 


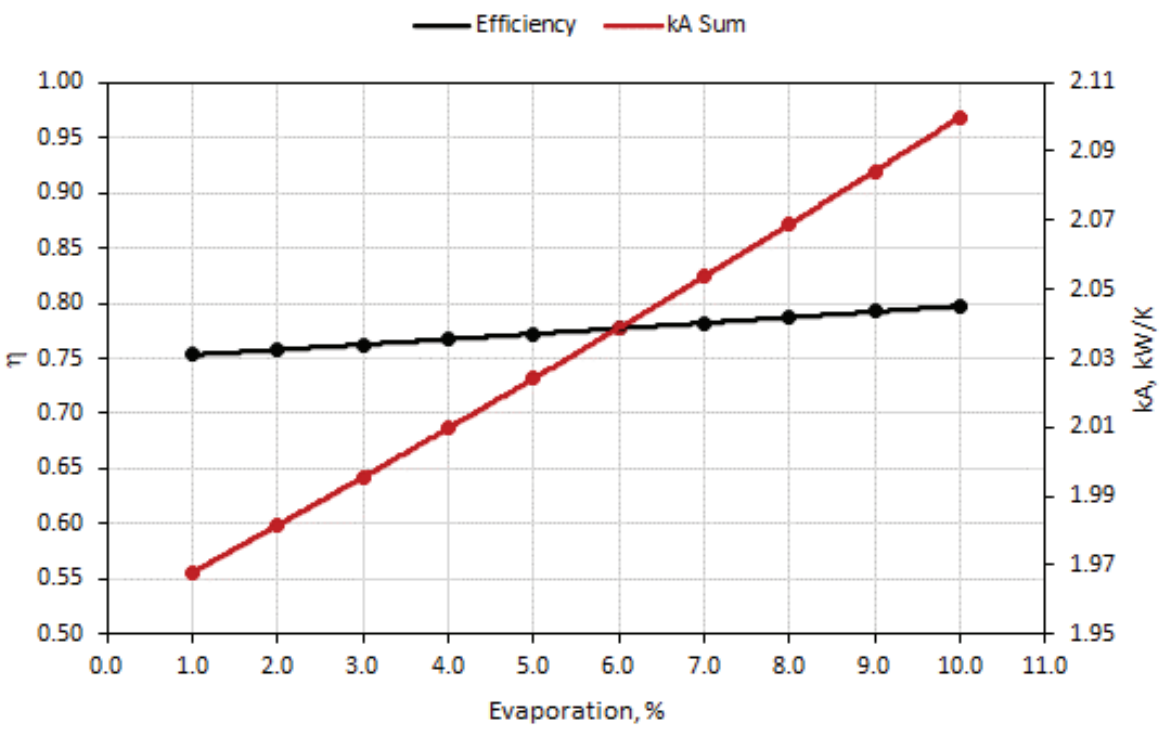

Fig. 5. Change in efficiency and in parameter kA for all the exchangers included in the cycle with a throttle valve depending on the adopted level of evaporation.

In order to analyse the operation of the cycle with the throttle valve at various loads, the previously mentioned case with the assumed evaporation level of 5\% was selected. Figure 6 shows the system characteristics for operation at different loads.

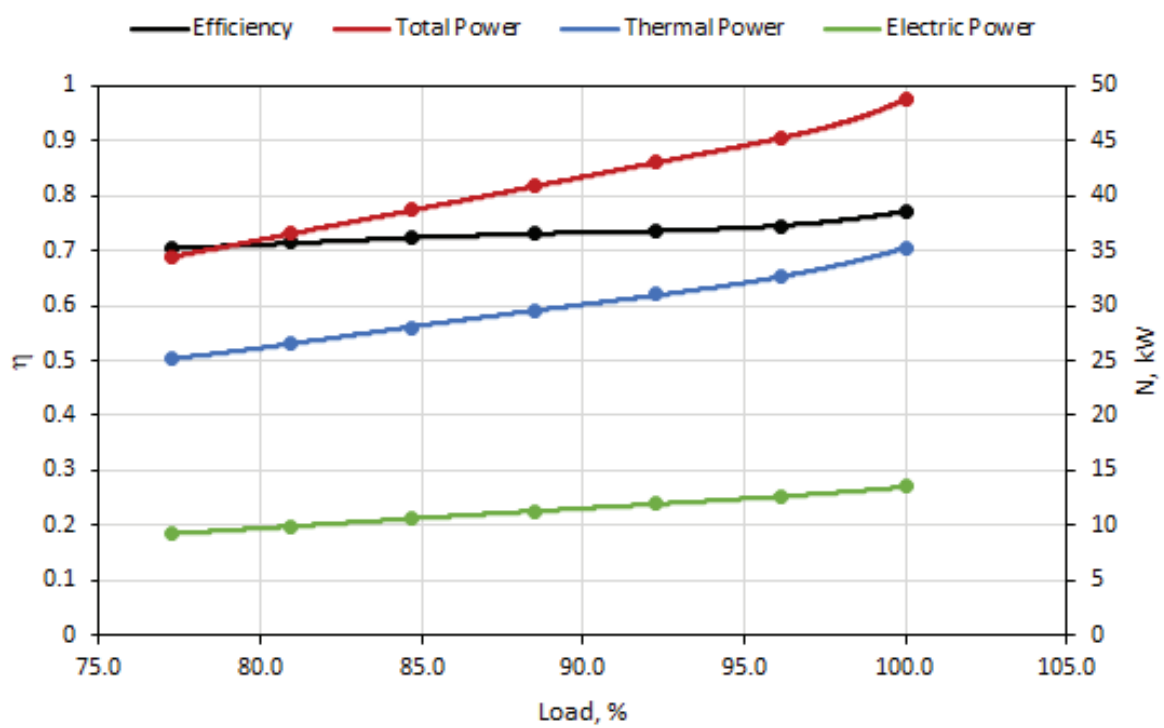

Fig. 6. Operating characteristics of the Velox-type CHP plant with a throttle valve for different loads ( $5 \%$ evaporation on the throttle valve).

It should be noted that this cycle is characterized by the fact that only for the nominal conditions will evaporation occur on the throttle valve because a change in load of the entire system is followed by a change in temperature downstream the economizer to values no 
longer corresponding to the saturation temperature for the pressure downstream the throttle valve. As shown in Fig. 6, efficiency and energy production for loads lower than 100\% drop dramatically, which is to be expected considering that below the rated load, after isenthalpic throttling, there is only water that is fed directly to the evaporator. It can also be seen that the availability of the proposed cycle varies within $77 \div 100 \%$ of the rated load.

In order to show the temperature changes at individual characteristic points in the cycle, Fig. 7 presents t-Q diagrams for the reference cycle and the cycle with a throttle valve at the evaporation level of $5 \%$.

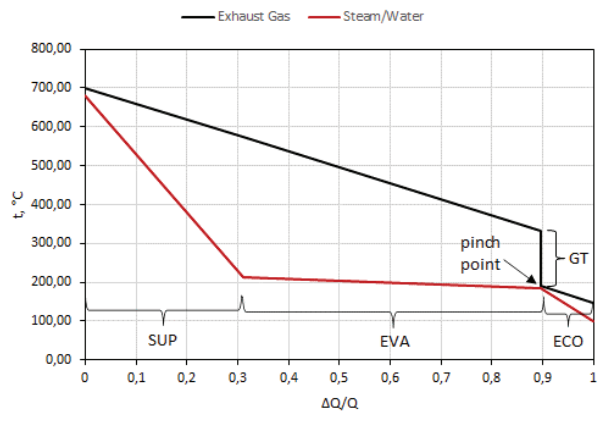

(a)

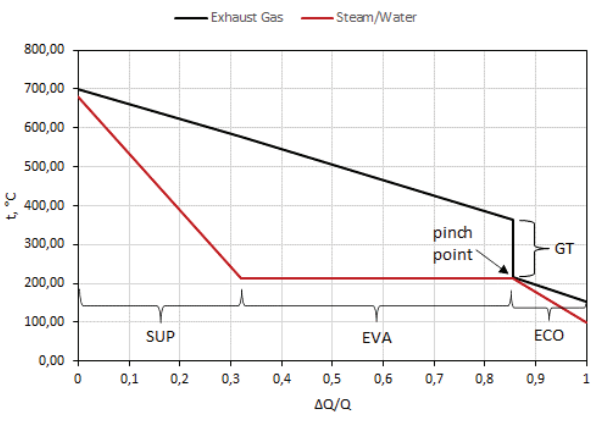

(b)

Fig. 7. T-Q diagrams of the reference cycle of the Velox-type CHP plant (a) and the Velox-type CHP plant with a throttle valve (5\% evaporation on the throttle valve) (b).

It can be clearly seen in Fig. 7 that for a cycle with a throttle valve, less heat is needed to evaporate the water in the evaporator (EVA). This is obviously due to some of the water evaporating in the throttle valve earlier. It can also be seen that the heat flux needed to superheat the steam (SUP) is almost identical for both cycles, and the amount of heat transferred in the economizer $(\mathrm{ECO})$ is greater in the cycle with a throttle valve.

In addition, the above diagrams show the effect of the gas expander (GT) on the temperature distribution in the cycle. This effect is characterized by the fact that the exhaust gas temperature drops between the evaporator and the economizer, but no heat is transferred to the working medium in the steam part of the cycle. Hence, a significant drop in temperature at the end of the cycle is visible in both diagrams.

\section{Simplified economic analysis}

The costs related to the plant were analysed using the relations commonly applied in the economic analysis of gas-steam power units [3, 8-9]. The presented relations take account of only the costs of the elements included in the plant. The costs related to transport, assembly, supervision or management of the whole project are omitted. Similar economic analyses were conducted earlier in [5], where details of the calculation of the total cost of the investment can be found.

The values obtained from the relations presented in [5] and expressed in USD were updated in 2015 using the Chemical Engineering Plant Cost Index (CEPCI) and they are presented in Fig. 7 for the reference cycle of the Velox-type CHP plant and for the cycle with a throttle valve at 5\% evaporation. Assuming that the cost of the reference cycle equals $100 \%$, the obtained results indicate that the cost of the Velox-type steam-gas system with a throttle valve at $5 \%$ evaporation totals about $102 \%$ of the cost of the reference cycle. This means that the unit cost of the proposed cycle of the 
Velox-type CHP plant with a throttle valve is almost the same compared to the reference cycle.

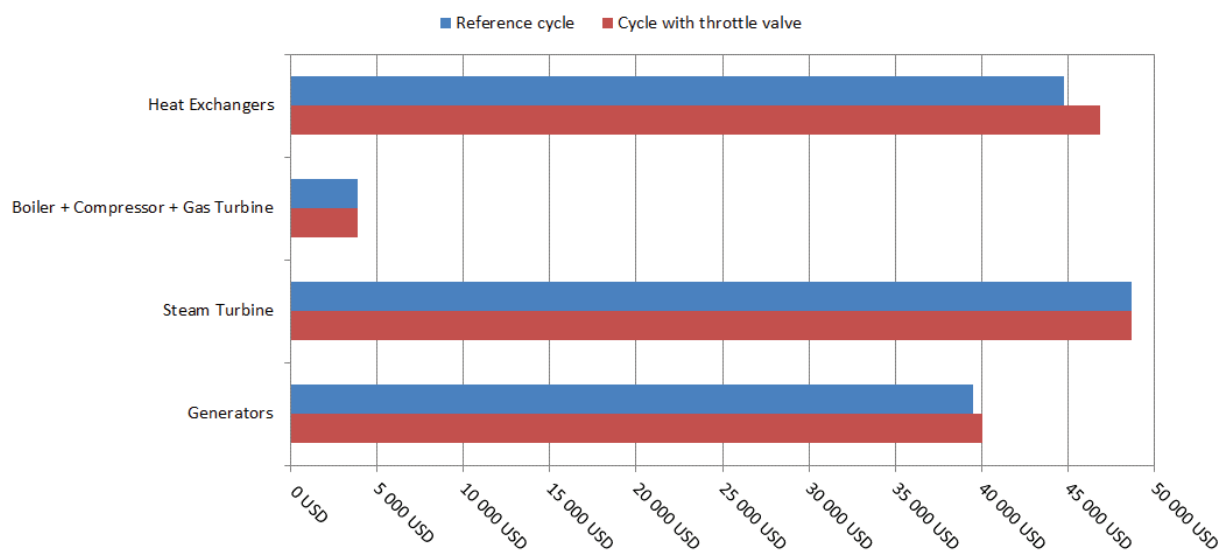

Fig. 7. Cost analysis - Velox-type CHP plant reference cycle and the cycle with a throttle valve at 5\% evaporation.

In addition, it can also be noticed that the costs of the steam turbine and the gas turbine, as well as of the compressor and the combustion chamber, are identical for both the reference cycle and the cycle with the throttle valve, which results directly from the adopted input data. The higher cost of all the heat exchangers installed in the cycle is due to the fact that the cycle with the throttle valve requires a bigger surface area of the heat exchange, and the higher cost of the generators is due to the higher power generated for the nominal load of the cycle with the valve.

\section{Conclusions}

The following conclusions can be drawn from the analyses of the Velox-type gas-steam combined heat \& power plant retrofitted with a throttle valve in the feed water circuit and from the comparison to the reference cycle:

- the cycle with the throttle valve achieves higher efficiency than the reference system assuming that the level of evaporation on the throttle valve is higher than $4 \%$,

- the electric power generated by the two compared cycles is almost identical, but the increment in the thermal energy production is more significant for the cycle with the throttle valve,

- the sum of the surface areas of all the heat exchangers in the reference cycle is slightly smaller compared to the cycle with the throttle valve, but this does not have a significant effect on the investment outlays related to the latter cycle,

- by vaporizing some of the feed water on the added throttle valve, it is possible to improve the efficiency of the retrofitted cycle, but only if it operates at the nominal conditions; the favourable effect of the valve in terms of energy conversion will be lost if load is reduced.

Summing up, the operation of a cycle with a throttle valve is favourable only in the nominal load conditions of the proposed cycle of the combined heat and power plant. This is probably the concept biggest downside because in this way the availability of the analysed cycle is decreased. Despite the fact that the investment outlays related to the construction of the proposed cycle are only slightly different compared to the reference cycle, the operating costs of the cycle with the throttle valve may rise considerably at operation at loads lower than 
nominal. The cycle of a Velox-type gas-steam cogeneration plant with an added throttle valve can find application in distributed power engineering or in industrial plants where higher production of heat than electricity is required under the condition of operation close to the $100 \%$ load.

The presented work was supported by the Silesian University of Technology within Statutory Research Funds.

\section{References}

1. The Brown Boveri Review Issued by Brown, Boveri \& Company, Limited, Baden (Switzerland), Vol. XXXI, January/February 1944, Nos. 1/2.

2. A. Wędzik, Energetyka 5, 323-329 (2006) (in Polish).

3. Ł. Bartela, "Optymalizacja termodynamiczna oraz ekonomiczna pracy elektrociepłowni gazowo-parowej" ["Thermodynamic and economic optimization of the gas-steam CHP plant operation"] (in Polish), Ph.D. thesis, Silesian University of Technology, 2009.

4. S. Dykas., J. Kotowicz, K. Smołka, Rynek Energii 4(95), 47-52 (2011) (in Polish).

5. K. Smołka, S. Dykas, S. Rulik, "A comparative analysis of the performance of a steamgas system of a Velox-type cycle and a gas-steam power station using a waste-heat boiler" in Proceedings of the 4th International Conference on Contemporary Problems of Thermal Engineering (2016), pp. 229-236.

6. K. Smołka, S. Dykas, Journal of Power Technologies 97(5), 343-348 (2017).

7. K. Smołka, S. Dykas, E3S Web of Conferences 137, 01001 (2019).

8. J. Kotowicz, Ł. Bartela, Energy 35(2), 911-919 (2010).

9. L. Attala, B. Facchini, G. Ferrara, Energy Conversion and Management 42(18), 2163 2172 (2001). 